\title{
Internet Addiction, Leisure Boredom and Relationship Satisfaction Among Young Adults
}

\author{
Ms. Avya Mathur ${ }^{1 *}$, Ms. Shreya Saxena ${ }^{2}$, Dr. Zuby Hasan ${ }^{3}$
}

\section{ABSTRACT}

In the 21 st century, where every other individual has access to the Internet, the chances of spending too much time surfing it becomes higher. In recent times, the Covid-19 virus has taken a toll on our mental health, and the Internet has become our only source of communication with the outside world. Through the present study, we aimed at understanding the relationship between internet addiction and leisure time and how it impacts our social relationships. Three scales were used to form a survey questionnaire that assessed respective aspects. The sample consisted of 120 participants (60 males and 60 females), and the data was collected using the Snowball Sampling technique. Internet addiction affects our mental health and can result in physical problems like problems in vision, headaches, weight gain/weight loss, and body aches. In contrast, mental issues like depression, anxiety, and social withdrawal can also take place. The research would further find and analyze more aspects where Internet Addiction plays a role.

\section{Keywords: Covid-19, Internet Addiction, Leisure Boredom, Relationship Satisfaction}

7 he year 2020 has not only impacted our physical health but has also taken a toll on our mental well-being. With lockdowns and social distancing taking place, entirely professional and personal life came down to the Internet. With the availability of the Internet to everyone, the possibilities of humans getting addicted to it become higher. Internet addiction can be described as any behaviour in which a person becomes dependent on the Internet. It can include spending the majority of the day surfing the Internet and not focusing on other daily activities. It has been found that internet addiction can cause vision problems, body aches, depression, social isolation, aggression, and anxiety. Many factors can lead to internet addiction, but the most common factors would be Leisure \& Boredom.

Leisure is described as the time that is free from work, school, or other daily responsibilities. For example, for a student, leisure time would be after their schoolwork ends. Similarly, for

\footnotetext{
${ }^{1}$ BA (H) Applied Psychology student, Amity Institute of Psychology and Allied Sciences, Amity University, Noida, India.

${ }^{2}$ BA (H) Applied Psychology student, Amity Institute of Psychology and Allied Sciences, Amity University, Noida, India.

${ }^{3}$ Faculty, Amity Institute of Psychology and Allied Sciences, Amity University, Noida, India *Corresponding Author
}

Received: September 17, 2021; Revision Received: October 04, 2021; Accepted: October 23, 2021

(C) 2021, Mathur A., Saxena S. \& Hasan Z.; licensee IJIP. This is an Open Access Research distributed under the terms of the Creative Commons Attribution License (www.creativecommons.org/licenses/by/2.0), which permits unrestricted use, distribution, and reproduction in any Medium, provided the original work is properly cited. 
a businessman, leisure time could be when they do not have any client calls or work responsibilities. On the other hand, boredom is an emotional and occasionally psychological state experienced when an individual is left without anything in particular to do, is not interested in their surroundings, or feels that a day or period is dull.

Researches have proved that there exists a positive relationship between leisure boredom and internet addiction. The possible reasons for this relationship in the times of Covid-19 could be that we all have spent the past nine months sitting at home and working through the Internet. As a result, we had experienced more leisure time than the times when we had to work outside our houses. Hence, the possibility of internet addiction among adults has been increased as the Internet is now the only way we can connect with our dear ones.

Apart from the physical and mental health impacts, Internet addiction has also impacted the relationship satisfaction of people. It can be seen that people who invest their time more on the Internet have lower relationship satisfaction. The reasons could be time issues, including not giving enough time to the partner or family members. In addition, with most time spent on the Internet, the person may lack social skills and negatively impact their interpersonal relationships. One of the most common examples can be that of a parent-child relationship. If the child is addicted to the Internet, the relationship between the parent and child will get affected negatively as there would be less family time.

Therefore, it can be said that most of us are bored in our leisure time. With the advanced technology and Covid-19 crisis, we choose to use that time on the Internet instead of doing other activities like meeting friends, reading books, or simply going out for a walk.

\section{Objectives:}

- To understand the relationship between internet addiction and leisure boredom.

- To understand if and how internet addiction impacts the relationship satisfaction of an individual.

- To gauge the gender differences that might be present among males and females regarding internet addiction.

\section{Hypothesis:}

- There would be no significant difference among males and females regarding Internet Addiction in the present scenario.

- There would be a meaningful relationship between internet addiction and leisure boredom amongst young adults.

- There would be a significant relationship between internet addiction and relationship satisfaction of young adults.

\section{REVIEW OF LITERATURE}

Marzilli, Cerniglia, Ballorotto and Cimino (2020) studied the relationship between young adults' gender and Internet addiction and other mediating factors that may exist. The study was conducted $56.6 \%$ males out of 244 young adults who lie within 19 to 25 years. The results of this particular study suggested that there is no significant gender difference in terms of Internet addiction. However, the individuals who were mildly addicted to the Internet had poor family involvement. 
Hassan, Alam Wahab and Hawlader (2020) studied the prevalence of Internet Addiction among young adults and attempted to examine the factors that may be associated. The study consisted of 454 participants in total, where 247 were males, and 207 were females. The survey conducted included Young'sYoung's Internet Addiction scale to collect data. The findings showed that males were found to be more prone to internet addiction as compared to females. It was also noticed people who had familial detachment showed higher signs of Internet addiction.

Demircioglu and Köse (2018) tried to understand the relationship between social media addiction and how it relates to our relationship satisfaction and its role in our lives. This comprehensive study included 229 participants who were accessed based on pre-existing questionnaires. The findings of this particular study suggest a negative relationship between what is known as social media addiction and relationship satisfaction. Basic observation can understand that once a person starts to spend more and more time in the virtual world of social media and the Internet, they begin to lose touch with reality and hence develop a negative dissatisfactory relationship with the people they are surrounded with.

Another detailed study done by Esra CIZZMECI (2017) connected and brought an explanation to the relationship that phubbing (excessive use of your mobile device, so much so that it leads to the ignorance of people around) has with one's relationship satisfaction. The 500 participants that participated in this study were assessed based on two scales, and the results showed that this behaviour of phubbing does not significantly impact the relationships negatively. One of the reasons the researcher attributes to this is that the participants might not be willing to break the traditional bounds and respond as they genuinely want to. Phubbing is a very widely recognized and accepted phenomenon in relationships, which doesn't impact those in one.

Porter, Mitchell, Grace, Shinosky \& Gordon (2012) researched to study the basic outline of what formulates the relationship satisfaction among young adults within their interpersonal relationships and the impact that being addicted to the Internet may have on this perception of their satisfaction. The sample size incorporated in this study included 219 participants within the age range of 18 to 25 years and were asked to respond to two scales. The findings suggest that the relationship between internet addiction and relationship satisfaction is significantly negative for young adults. A primary reason that can be attributed to this phenomenon is that most people are already satisfied with their relationships. With the development in and around us, the primary mode of communication has shifted over to social media and the Internet, increasing the relationship binding and satisfaction overall.

Chien-Hsin Lin, Shong-Lin Lin, and Chin-Pi Wu (2009) researched to understand the effects of the way an individual's parental monitoring and leisure boredom can impact their internet addiction. The study included 1289 participants, and these participants were accessed over four questionnaires, including the Leisure boredom scale developed by Iso-Aloha and Weissinger. The intriguing results of this particular study suggested that while there exists no difference between internet addiction in the male and female population, male members, being more involved in outdoor, social and Internet activities, are more prone to developing internet addiction than females.

Louis Leung, PhD (2008), conducted a detailed study to find out the complex relationship between leisure boredom, sensation seeking, the self-esteem of an individual, and what patterns a person exhibits while being addicted to mobile phones. A sample of 624 teenagers 
and young adults ranging in age from 14 to 28 was used for the study. The interview was done via telephone on the same sample. The four significant reasons found to have a role in making a person internet and mobile phone addicted include the inability to control the urge to use their mobile phones, the feelings of anxiousness and being lost without the Internet, along with withdrawal and escape and productivity loss.

Liu and Kuo (2007) did a study to identify the predictors and causes of internet addiction and related to one's interpersonal relationships. The study incorporated 555 participants who were assessed based on four scales: Parent-Child relationship scale, Interpersonal relationships scale, Social anxiety scale, Internet Addiction scale. This study found that individuals addicted to the internet experience more social anxiety and often have bad personal relations with others. However, this anxiety can be overcome with good support from parents and guardians and focusing on good parent-child relationships early in childhood.

\section{METHODOLOGY}

Participants: The study included 120 participants, 60 male and 60 female ranging from 18 30 years of age. $67.5 \%$ of the population are students, and $32.5 \%$ are non-students.

Measures: The survey questionnaire consisted of three subscales:

- Internet Addiction Test (IAT; Young, 1998) aims to measure the severity of compulsive internet use among individuals. This is a self-report test consisting of 20 items, including questions about how their internet use impacts their daily functioning and to what extent. The respondent can choose from a continuum of 6point Likert scale ranging from 0 beings' beings' not applicable" to 5 being "always" for a given situation. A high score on this test indicates more significant levels of addiction towards the Internet.

- Leisure-Boredom Scale (LBS; Iso-Ahola \& Weissinger, 1990) measures the level of boredom an individual perceives in their free or leisure time. The scale consists of 16 Likert-type items. Individuals are required to answer to the given situations in each item on a scale of 1 being "strongly disagree" and five beings "strongly agree", where a few things are also scored in a reverse manner. A high score on this scale indicates a higher level of perceived boredom in an individual's leisure time.

- Burns Relationship Satisfaction Scale (BRSS; Burns, David D., 1993); This scale is a seven-item inventory that measures the level of satisfaction an individual holds in various areas of a relationship, including the communication and caring in a relationship. This self-report scale provides the respondents with a continuum of responses ranging from 0 to very dissatisfied and six to very satisfied. A higher score on this scale suggests a greater level of satisfaction within the relationship.

\section{Procedure}

To measure the variables accurately, questionnaires that fulfilled the requirements were chosen, keeping in mind the reliability and validity of the scales (IAT, LBS, BRSS). Further, a survey was framed using Google Forms which comprised three sections for the respective questionnaires. To follow the ethical procedures, the participants were asked for their consent before they filled the questionnaire. Finally, the survey was shared with the subjects. Data was collected using the Snowball Sampling Technique. After data collection, the scoring was done with the help of scoring keys mentioned in the questionnaires. 


\section{Analysis}

The data were analyzed using SPSS statistics. First, the mean and standard deviation were calculated, along with which the correlation between each of the three variables was computed using the scores collected from the Internet Addiction Test (IAT), Leisure Boredom Scale (LBS) and Burns Relationship Satisfaction Scale (BRSS). Then, the correlation coefficients were analyzed to understand how internet addiction is related to their perception of boredom in leisure time and how it impacts their relationship satisfaction. The significance was analyzed on both two-tailed (.01 and .05) and 0.2 levels.

\section{RESULTS}

Table 1 represents the standard deviation scores, mean, along with error of the mean for both male and female participants using the scores of the three scales Internet Addiction Test, Leisure Boredom Scale, Burns Relationship Satisfaction Scale. Table 2 represents the tvalues for both sexes for the three scales, whereas table 3 depicts the correlation values between the Internet Addiction Test, Leisure Boredom Scale, Burns Relationship Satisfaction Scale.

Table 1: Group Statistics

\begin{tabular}{|l|l|l|l|l|l|}
\hline & Gender & $\mathbf{N}$ & Mean & Std. Deviation & Std. Error Mean \\
\hline \multirow{2}{*}{$\begin{array}{l}\text { Internet } \\
\text { Addiction }\end{array}$} & males & 60 & 39.0000 & 14.07245 & 1.81675 \\
\cline { 2 - 6 } & females & 60 & 34.0833 & 13.89097 & 1.79332 \\
\hline \multirow{2}{*}{$\begin{array}{l}\text { Leisure } \\
\text { Boredom }\end{array}$} & males & 60 & 41.5833 & 7.47944 & .96559 \\
\cline { 2 - 6 } & females & 60 & 41.0667 & 8.06933 & 1.04175 \\
\hline \multirow{2}{*}{$\begin{array}{l}\text { Relationship } \\
\text { Satisfaction }\end{array}$} & males & 60 & 26.4833 & 8.53208 & 1.10149 \\
\cline { 2 - 6 } & females & 60 & 30.6333 & 7.57777 & .97829 \\
\hline
\end{tabular}

Table 2: Correlation between Internet Addiction Test (IAT), Leisure Boredom (LB) and Relationship Satisfaction (RS)

\begin{tabular}{|c|c|c|c|c|}
\hline & & IAT & LB & RS \\
\hline \multirow[t]{3}{*}{ IAT } & Pearson Correlation & 1 & .142 & -.125 \\
\hline & Sig. (2-tailed) & & .123 & .175 \\
\hline & $\mathrm{N}$ & 120 & 120 & 120 \\
\hline \multirow[t]{3}{*}{ LB } & Pearson Correlation & .142 & 1 & -.086 \\
\hline & Sig. (2-tailed) & .123 & & .350 \\
\hline & $\mathrm{N}$ & 120 & 120 & 120 \\
\hline \multirow[t]{3}{*}{ RS } & Pearson Correlation & -.125 & -.086 & 1 \\
\hline & Sig. (2-tailed) & .175 & .350 & \\
\hline & $\mathrm{N}$ & 120 & 120 & 120 \\
\hline
\end{tabular}


Table 3: Independent Samples Test; significance at 2 tailed levels; Internet Addiction Test (IAT), Leisure Boredom (LB) and Relationship Satisfaction (RS)

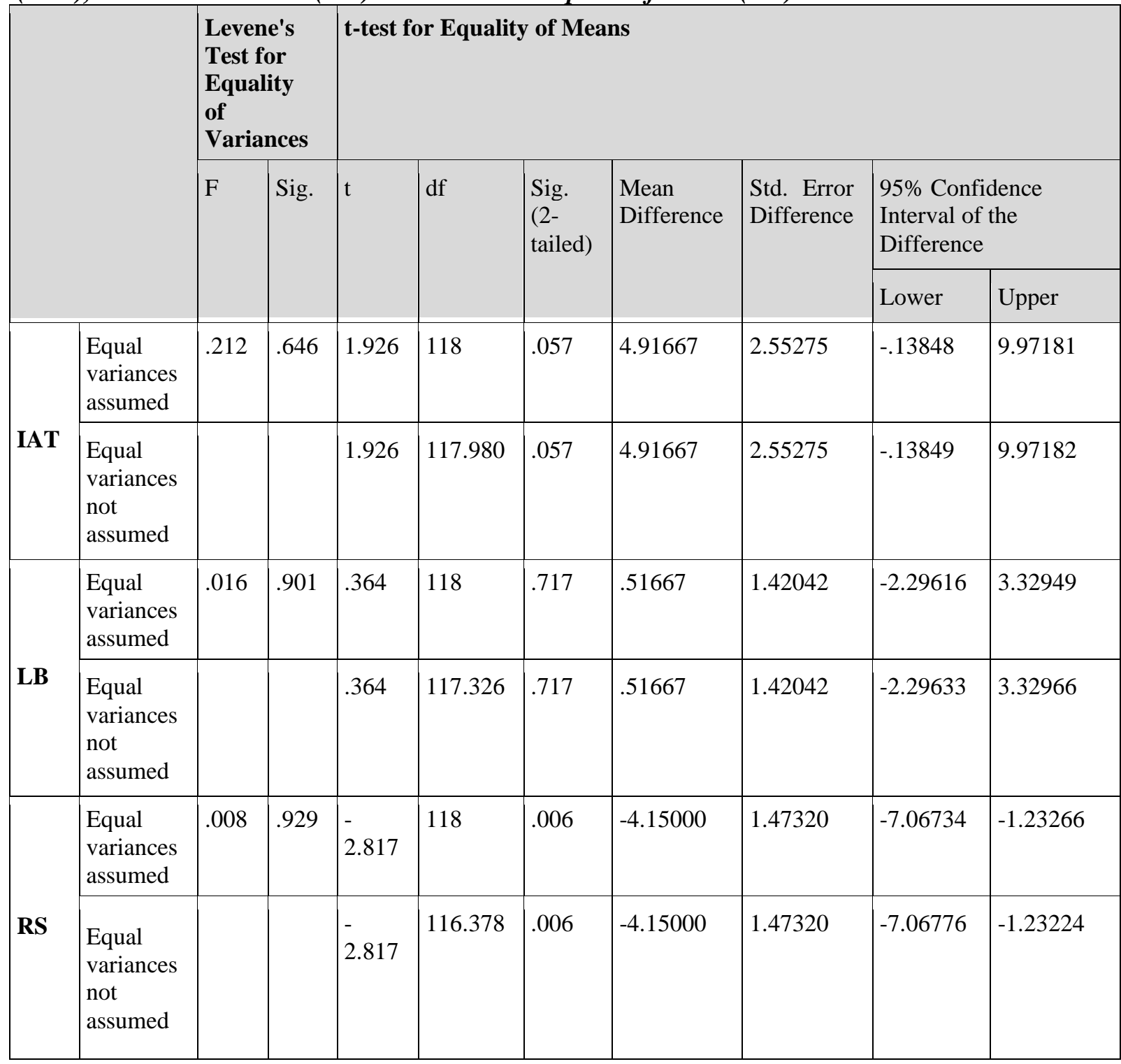

\section{DISCUSSION}

This study majorly aimed to understand the relationship between internet addiction and leisure boredom and what impact does internet addiction have on the relationship satisfaction of young adults. The current study provided us with an insight into how gender is related to our three variables. As shown in table number 2, the findings of this study suggest that there were no significant gender differences in terms of internet addiction amongst male and female participants. Research done before suggests contrary results, as they have portrayed that males are more prone to internet addiction than females (Hassan, Alam, Wahab and Hawlader, 2020). However, one of the studies suggested no significant difference between males and females in terms of internet addiction when talking about the present scenario (Marzilli, Cerniglia, Ballarotto and Cimino, 2020). This finding can be supported by the fact that both genders have been dependent on the Internet in terms of working from home and connecting with their loved ones during the pandemic time. Hence, we might not see any significant difference between the usage of the Internet between the two. 
When it comes to leisure boredom, no significant difference exists between the two genders. However, when talking about relationship satisfaction, it was seen that females tend to be more satisfied in their close intimate relationships rather than males, pointing towards the fact that females who might be addicted to the Internet may overcome it with the help of social support and care from their families.

However, we found no correlation between the three variables (internet addiction, leisure boredom and relationship satisfaction). This can be explained by the fact that the concept of leisure boredom has been dynamically changed during this pandemic, specifically for young adults. Since most of their work has been done over the Internet, it does not have anything to do with the leisure time they get.

Coming to the quality of relationships that people have in the current scenario, the meaning of relationships has also evolved as people cannot meet each other physically. With less proximity and sudden change, parameters like intimacy, communication and closeness have significantly decreased. Contrary to this, the Internet is the primary source of communication that has brought people together and has given them comparatively more time to give each other. Hence, this can be the reason why there was no significant impact of internet addiction on relationships. In one of the studies done by Liu and Kuo (2007), it was found that internet addiction is majorly related to bad interpersonal relationships and parentchild relationships with a mediating role of social anxiety. However, consistent with our findings, the time people have spent together in the current scenario has somehow pushed them to maintain healthy and well-balanced relationships, hence having no specific effect on internet addiction.

\section{Suggestions and recommendations}

Since young adults are exposed to almost every platform of social media, it is important to spread knowledge of what is negative in their lives and how they can change their thoughts and perceptions. The Internet can impact an individual in either a positive or negative way. Therefore, using too much Internet can hamper our personal and interpersonal relationships. When we talk about interpersonal relationships, they don't pertain only to our significant other's but also our family members. So even though relationships with partners have shown a positive effect, it's also essential to consider family.

When a child gets addicted to the Internet, the chances of social isolation becomes higher. This can negatively impact the parent-child relationship as there would be less family time and more alone time. As a result, the child may drift apart from the parents even though they are between the same four walls. Furthermore, the negative relationship can lead to a lack of understanding and more quarrels and tantrums, hampering the connection. With various websites and programs available online, internet addiction is quite common amongst the youth.

Therefore it's essential to know when and where to stop surfing. To understand a few through which internet surfing can be reduced, one can practice self-control, which means blocking out the distracting websites for some time. Another way is to concentrate by maximizing focus when shifting from one task to another. FocusBooster is also a technique used by many people to control internet addiction; this means that every single task is assigned 25 minutes to it, not more and not less. Finally, rest, some basic and easy ways to start your journey towards internet-free life is to take some time out for yourself, set timers and alarms on your phone, meditation or engage with people around you. 


\section{Scope for further research}

This study aims at understanding the complex relationship between internet addiction present amongst young adults, how it is related to their perception of boredom in their leisure time and what impact it has on their relationship satisfaction. Gender differences based on internet addiction, leisure boredom and relationship satisfaction were also examined within this research paper. We found no significant correlation between the three variables, which can be explained by the visibly changing dynamics of society and environment and how it has impacted us as an individual. Apart from this, our findings suggest that females tend to be more satisfied within their close relationships than males, which might help them cope with internet addiction.

\section{CONCLUSION}

This study aims at understanding the complex relationship between internet addiction present amongst young adults, how it is related to their perception of boredom in their leisure time and what impact it has on their relationship satisfaction. Gender differences on the basis of internet addiction, leisure boredom and relationship satisfaction were also examined within this research paper. We found that there exists no significant correlation between the three variables, which can be explained by the visibly changing dynamics of society and environment and how it has impacted us as an individual. Apart from this, our findings suggest that females tend to be more satisfied within their close relationships than males, which in turn also might help them cope with internet addiction.

\section{REFERENCES}

Cizmeci, E. (2017). Disconnected, though satisfied: Phubbing behaviour and relationship satisfaction. The Turkish Online Journal of Design, Art and Communication, 7(2), 364-375.

Demircioğlu, Z. I., \& Köse, A. G. (2018). Effects of attachment styles, dark triad, rejection sensitivity, and relationship satisfaction on social media addiction: A mediated model. Current Psychology, 1-15.

Hassan, T., Alam, M. M., Wahab, A., \& Hawlader, M. D. (2020). Prevalence and associated factors of internet addiction among young adults in Bangladesh. Journal of the Egyptian Public Health Association, 95(1), 3.

Kara, F. M. (2019). Internet Addiction: Relationship with Perceived Freedom in Leisure, Perception of Boredom and Sensation Seeking. Higher Education Studies, 9(2), 131140.

Leung, L. (2008). Leisure boredom, sensation seeking, self-esteem, and addiction. Mediated interpersonal communication, 1, 359-381.

Lin, C. H., Lin, S. L., \& Wu, C. P. (2009). THE EFFECTS OF PARENTAL MONITORING AND LEISURE BOREDOM ON ADOLESCENTS' INTERNET ADDICTION. Adolescence, 44(176).

Liu, C. Y., \& Kuo, F. Y. (2007). A study of Internet addiction through the lens of interpersonal theory. CyberPsychology \& Behavior, 10(6), 799-804.

Marzilli, E., Cerniglia, L., Ballarotto, G., \& Cimino, S. (2020). Internet addiction among young adult university students: the complex interplay between family functioning, impulsivity, depression, and anxiety. International journal of environmental research and public health, 17(21), 8231.

Porter, K., Mitchell, J., Grace, M., Shinosky, S., \& Gordon, V. (2012). A study of the effects of social media use and addiction on relationship satisfaction. Meta-communicate, 2(1). 
Raju, N. J., Valsaraj, B. P., \& Noronha, J. A. (2014). Online social networking among professional students: Impact on interpersonal relationships. International Journal of Scientific Engineering and Technology, 3(3), 289-292.

\section{Acknowledgement}

We would like to thank all the participants for providing us with their information and donating some of their essential time to help us with our research. We assure the participants that their data would be kept highly confidential. We would also like to thank the IJIP Journal for providing us with the opportunity to publish our paper for other educational purposes. Lastly, we also want to thank all the people who helped us throughout this research with their support.

\section{Conflict of Interest}

The author(s) declared no conflict of interest.

How to cite this article: Mathur A., Saxena S. \& Hasan Z. (2021). Internet Addiction, Leisure Boredom and Relationship Satisfaction Among Young Adults. International Journal of Indian Psychology, 9(4), 60-68. DIP:18.01.007.20210904, DOI:10.25215/0904.007 